\title{
Power plant wastes capitalization as geopolymeric building materials
}

\author{
Gabriela Ciobanu ${ }^{1}$,Loredana Litu ${ }^{1}$, and Maria Harja ${ }^{1, *}$ \\ 1"Gheorghe Asachi” Technical University of Iasi, Faculty of Chemical Engineering and \\ Environmental Protection, Prof. dr. doc. D. Mangeron Street no. 73, 700050, Iasi
}

\begin{abstract}
In this innovative study, we are present an investigation over the properties of geopolymeric materials prepared using ash supplied by power plant Iasi, Romania and sodium hydroxide solutions/pellets. Having as objective a minimum consumption of energy and materials was developed a class of advanced eco-materials. New synthesized materials can be used as a binder for cement replacement or for the removal/immobilization of pollutants from waste waters or soils. It offers an advanced and low cost-effective solution too many problems, where waste must be capitalized. The geopolymer formation, by hydrothermal method, is influenced by: temperature $\left(20-600^{\circ} \mathrm{C}\right)$, alkali concentration (2M-6M), solid /liquid ratio (1-2), ash composition, time of heating $(2-48 \mathrm{~h})$, etc. The behaviour of the FTIR peak of $6 \mathrm{M}$ sample indicated upper quantity of geopolymer formation at the first stage of the reaction. XRD spectra indicated phases like sodalite, faujasite, Na-Y, which are known phases of geopolymer/zeolite. Advanced destroyed of ash particles due to geopolymerisation reaction were observed when the temperature was higher. At the constant temperature the percentage of geopolymer increases with increasing of curing time, from 4-48 h. Geopolymer materials are environmentally friendly, for its obtaining energy consumption, and $\mathrm{CO}_{2}$ emission is reduced compared to cement binder.
\end{abstract}

\section{Introduction}

Geopolymers are a relatively new amorphous alumino-silicate with best properties such as mechanical resistance, thermal stability, durability, hardness, chemical stability, corrosion stability, etc. [1,2]. Geopolymers show characteristics of low shrinkage and excellent heat resistance. Geopolymer binder can be used as a partial or complete replacement of conventional cement to produce concrete [3-5]. Geopolymer concretes can be used in building, repairing infrastructures, in livestock, construction etc.

The geopolymers have empirical formula: $\mathrm{Me}_{\mathrm{x}}\left[-\left(\mathrm{SiO}_{2}\right)_{\mathrm{y}}-\mathrm{AlO}_{2}\right]_{\mathrm{x}} \mathrm{zH}_{2} \mathrm{O}$, where y is 1,2 or 3; $\mathrm{Me}$ is an alkali cation, such as potassium or sodium, and $\mathrm{x}$ is the degree of polymerisation [4-9].

Geopolymer binders can be produced from materials containing $\mathrm{Si}$ and $\mathrm{Al}$ ions. These can be raw materials or wastes (by-products) such as fly ash, ground granulated blast,

\footnotetext{
*Corresponding author: maria_harja06@yahoo.com
} 
furnace slag, metakaolinit or any other waste sources of Si and Al [5, 6, 10-13]. The material must be thermal activated in presence of sodium or potassium hydroxide, sodium metasilicate and water. Most frequently geopolymer, a novel eco-material, are prepared from fly ash and alkaline solution by different activation methods: sol-gel or diffusion methods at different temperatures. In the first stage raw materials are dissolved in high $\mathrm{pH}$ alkaline solution, process facilitated by heating, after this the geopolymers obtained are precipitated. In the process of the geo-polymerization reactions, polysialates, polysialate siloxo, and polysialate disiloxo are formed [14-16].

By using fly ash, first environmental and economic benefits of obtaining geopolymer eco-materials are due to capitalization a wastes from energy manufacture, $75 \%$ aren't used yet [7]. The second benefit is determined by the geopolymer binder is a low- $\mathrm{CO}_{2}$ cementious material; this technology can save up to $80 \%$ of $\mathrm{CO}_{2}$ emissions caused by the cement industry [9, 17]. On the other hand the geopolymerisation of fly ash offers environmental benefits, such as lower consumption of natural resources (limestone, clay etc.) and lower consumption of energy.

Previous publications on geopolymer materials investigated the effect of curing procedures, composition of the alkaline solution on strength development and hydration products, influence of temperature [18-23]. Other researchers demonstrated that geopolymer concrete is expensive comparatively with ordinary concrete [24].

In this paper, we present an investigation over the properties of geopolymeric materials prepared using ash supplied by power plant Iasi, Romania and sodium hydroxide solutions/pellets. Having as objective a minimum consumption of energy and materials was developed a class of advanced eco-materials. New synthesized materials, having pozzolanic properties, can be used as a binder for cement replacement or for the immobilization of pollutants from wastewaters or soils. It offers an advanced and low cost-effective solution to many problems, where waste must be capitalized. By minimizing the temperature of activation, and recycling the hydroxide solution, the cost of geopolymer is lower compared with the ordinary Portland cement.

\section{Experimental}

The fly ash (FA) sample supplied from power plant Iasi, was dehydrated in an oven at $105^{\circ} \mathrm{C}$, characterized and used throughout all experiments. The conditions used for the synthesis of geopolymeric eco-materials are presented in Table 1.

Table 1. Conditions of geopolymer synthesis.

\begin{tabular}{|c|c|c|c|}
\hline Sample & Method & Synthesis conditions & Activation time \\
\hline G1, G2 & \multirow{6}{*}{$\begin{array}{c}\text { Direct } \\
\text { activation }\end{array}$} & $1 / 2$ ratio, $6 \mathrm{M}, 20^{\circ} \mathrm{C}$ & 7 days, 21 days \\
\hline G3, G4 & & $1 / 2$ ratio, $2 \mathrm{M}, 50^{\circ} \mathrm{C}$ & $4 \mathrm{~h}, 8 \mathrm{~h}$ \\
\hline G5, G6 & & $1 / 2$ ratio, $4 \mathrm{M}, 50^{\circ} \mathrm{C}$ & $4 \mathrm{~h}, 8 \mathrm{~h}$ \\
\hline G7, G8 & & $1 / 2$ ratio, $2 \mathrm{M}, 80^{\circ} \mathrm{C}$ & $4 \mathrm{~h}, 8 \mathrm{~h}$ \\
\hline G9, G10 & & $1 / 2$ ratio, $4 \mathrm{M}, 80^{\circ} \mathrm{C}$ & $4 \mathrm{~h}, 8 \mathrm{~h}$ \\
\hline G11/ G12 & & $1 / 2$ ratio, $6 \mathrm{M}, 80^{\circ} \mathrm{C}$ & $4 \mathrm{~h}, 48 \mathrm{~h}$ \\
\hline G13, G14 & \multirow[t]{2}{*}{ Fussion } & $1 / 1$ ratio fly ash $/ \mathrm{NaOH}$ pellets, $600^{\circ} \mathrm{C}$ & $1 \mathrm{~h}, 2 \mathrm{~h}$ \\
\hline G15, G16 & & $1 / 2$ ratio fly ash $/ \mathrm{NaOH}$ pellets, $600^{\circ} \mathrm{C}$ & $1 \mathrm{~h}, 2 \mathrm{~h}$ \\
\hline
\end{tabular}

It can be observed from Table 1 that the synthesis of new eco-materials was carried out at ambient temperature, $50^{\circ} \mathrm{C}$ and $80^{\circ} \mathrm{C}$, respectively, in an alkaline medium with $\mathrm{NaOH}$ 
concentrations of $2 \mathrm{M}, 4 \mathrm{M}$ and $6 \mathrm{M}$, respectively, corresponding to a mixture with solid/liquid ratios of $1: 2$. In the case of G13-G16 samples synthesis was carried at $600^{\circ} \mathrm{C}$, with solid/solid ratios of 1:1 and 1: 2 using solid pellets, for 1 and $2 \mathrm{~h}$, by fusion method. After treatment, the geopolymer samples were crystallized for $18 \mathrm{~h}$; subsequently, they were filtered, washed at 8-8.5 value of $\mathrm{pH}$, and dried at oven at constant mass. In this study $\mathrm{NaOH}$ was produced by Chimcomplex Company.

SEM and EDAX were carried out with a Quanta 3D instrument AL99/D8229 (FEI Company), XRD analysis was conducted with an X'Pert PRO MRD X-ray diffractometer (PANalytical). The IR analysis was performed using a DIGILAB FTS 2000 spectrometer.

\section{Result and discussion}

For the studied fly ash the following chemical composition was obtained: $\mathrm{SiO}_{2}-49.82 \%$; $\mathrm{Al}_{2} \mathrm{O}_{3}-14.70 \% ; \mathrm{Fe}_{2} \mathrm{O}_{3}-4.44 \%$; CaO-6.21\%; MgO-0.96\%; $\mathrm{SO}_{3}-1.18 \%$; et all., in accord with literature [24-26]. The sum of $\mathrm{SiO}_{2}+\mathrm{Al}_{2} \mathrm{O}_{3}+\mathrm{Fe}_{2} \mathrm{O}_{3}$ is more than $70 \%$, the fly ash from Iasi power plant is class $\mathrm{F}$ [25]. The ratio $\mathrm{SiO}_{2} / \mathrm{Al}_{2} \mathrm{O}_{3}$ recommended the fly ash as raw materials for synthesis of geopolymeric and zeolite, fact demonstrated in previously research [27, 28]. The chemical composition, obtained by energy dispersive spectroscopic (EDAX) and elemental analysis of the synthesized materials, for four selected geopolymeric materials is presented in table 2. Its constituent particles have: $\mathrm{Si}, \mathrm{O}, \mathrm{Al}, \mathrm{K}$, $\mathrm{Na}, \mathrm{Mg}, \mathrm{Ca} \mathrm{Fe}$, Ti and $\mathrm{C}$.

Table 2. Chemical composition of geopolymeric materials.

\begin{tabular}{|c|c|c|c|c|c|c|c|c|c|}
\hline Sample & $\mathbf{O}$ & $\mathbf{N a}$ & $\mathbf{M g}$ & $\mathbf{A l}$ & $\mathbf{S i}$ & $\mathbf{K}$ & $\mathbf{C a}$ & $\mathbf{T i}$ & $\mathbf{F e}$ \\
\hline Fly ash & 43.32 & 0.79 & 0.6 & 19.09 & 30.81 & 1.75 & 1.05 & 0.54 & 2.05 \\
\hline G2 & 42.85 & 2.44 & 0.93 & 17.33 & 28.89 & 1.66 & 1.44 & 0.91 & 2.07 \\
\hline G6 & 42.93 & 4.42 & 0.78 & 17.37 & 23.38 & 2.09 & 1.19 & 0.79 & 2.51 \\
\hline G9 & 42.77 & 7.75 & 1.18 & 16.38 & 23.22 & 0.48 & 1.40 & 0.93 & 2.28 \\
\hline G16 & 40.37 & 10.87 & 1.28 & 16.31 & 24.10 & 0.61 & 1.69 & 0.82 & 2.07 \\
\hline
\end{tabular}

The FTIR spectra obtained for four geopolymeric material are presented in Fig. 1.
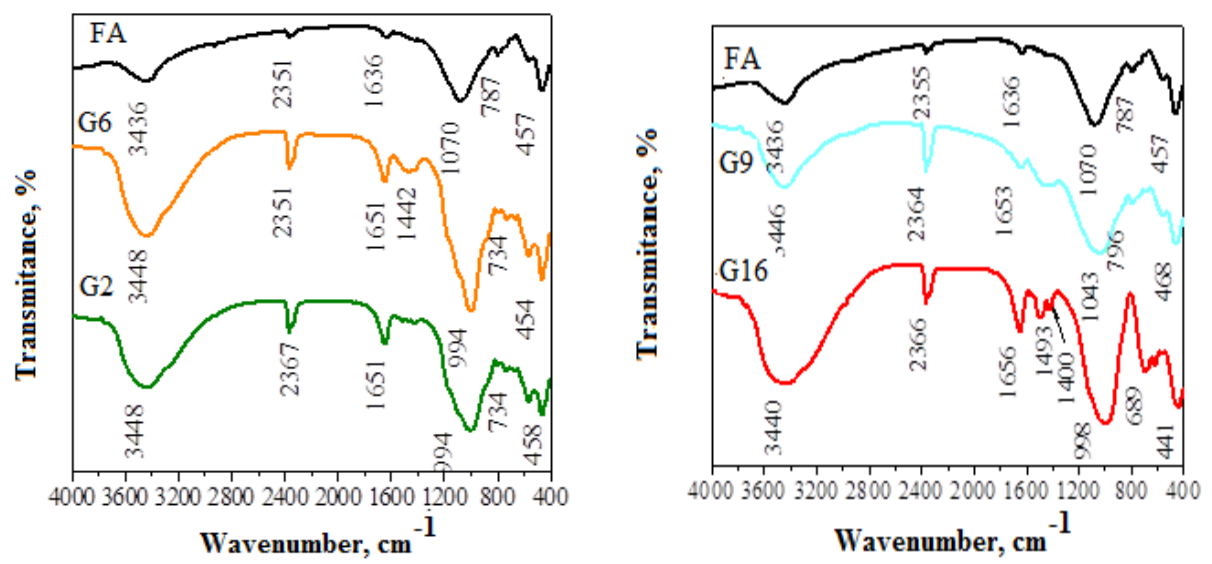

Fig. 1. FTIR spectra for fly ash and synthetized materials. 
From Fig. 1 it can be observed that comparing with fly ash the most relevant band is moving in the direction of wavenumber decreasing from $1075-1080 \mathrm{~cm}^{-1}$ to 995-1001 $\mathrm{cm}^{-1}$, that means appearance of new bending vibrations in the structure of synthesized material. Same representative picks were recorded between $993 \mathrm{~cm}^{-1}$ and 1001 $\mathrm{cm}^{-1}$ corresponding to asymmetric stretching $\mathrm{Si}-\mathrm{O}-\mathrm{Si}$ and $\mathrm{Al}-\mathrm{O}-\mathrm{Si}$. The metakaolinite ( $\mathrm{Si}-\mathrm{O}-1050 \mathrm{~cm}^{-1}$ ) band moving to $990 \mathrm{~cm}^{-1}$. Bands corresponding to alumino-silicates compounds are around $995 \mathrm{~cm}^{-1}$. Other characteristics bands for inorganic polymer (geopolymer) are 695 and $445-460 \mathrm{~cm}^{-1}$, when there is occur substitution of Si by Al [13, 29 , 30].The bands that occur within 500-650 $\mathrm{cm}^{-1}$ indicating the silicate and alumino-silicate vitreous phase $[2,4,5,18,29]$.

Geopolymerisation rates are determined from the intensity variation of the bands associated to the geopolymer gel network/unreacted fly ash. In the first step have an initial period (induction), followed by gel evolution by network formation. The period of induction is diminished by increasing the alkaline solution concentration. The increasing of $\mathrm{NaOH}$ concentration determines increase rate of network formation [30].

Influence of temperature over materials morphology is presented in Fig. 2. Experimental studies had shown that a proportion of spherical particles of initial fly ash are found in the materials obtained at temperatures up to $100^{\circ} \mathrm{C}$, while increase temperature to $600{ }^{\circ} \mathrm{C}$ determines an advanced destroy of particles [31, 32]. Temperature is an important parameter in obtaining geopolymeric materials. Increasing of the temperature determines accelerated of chemical reactions with changing of crystalline network, Fig. 2.
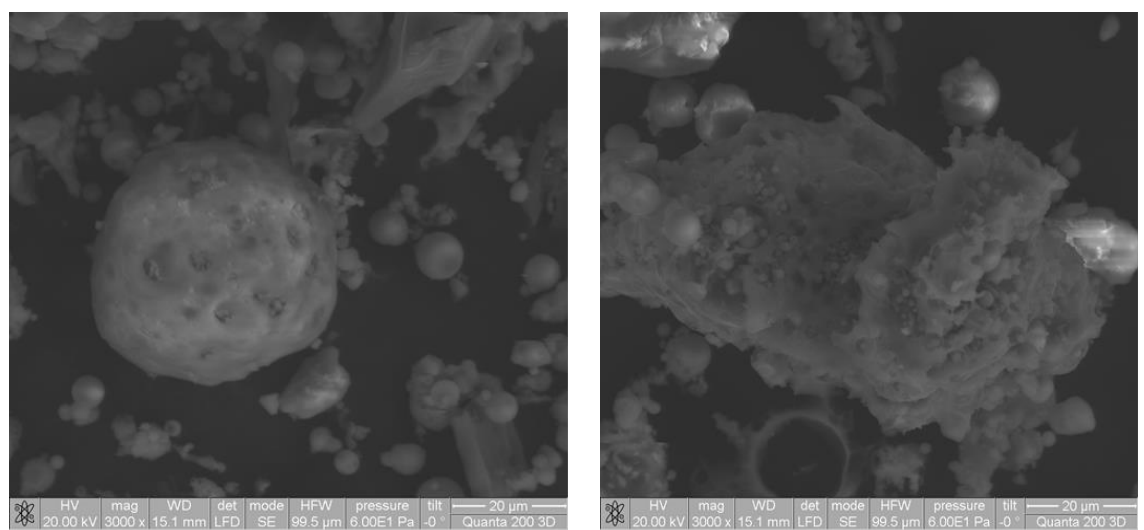

Fig. 2. Influence of temperature, activation method (G5 and G9).

The temperature increase, for fusion method, causes the most significant changes, with appearances of rhombohedra crystals, which mainly growing on the old solid, Fig.3. 

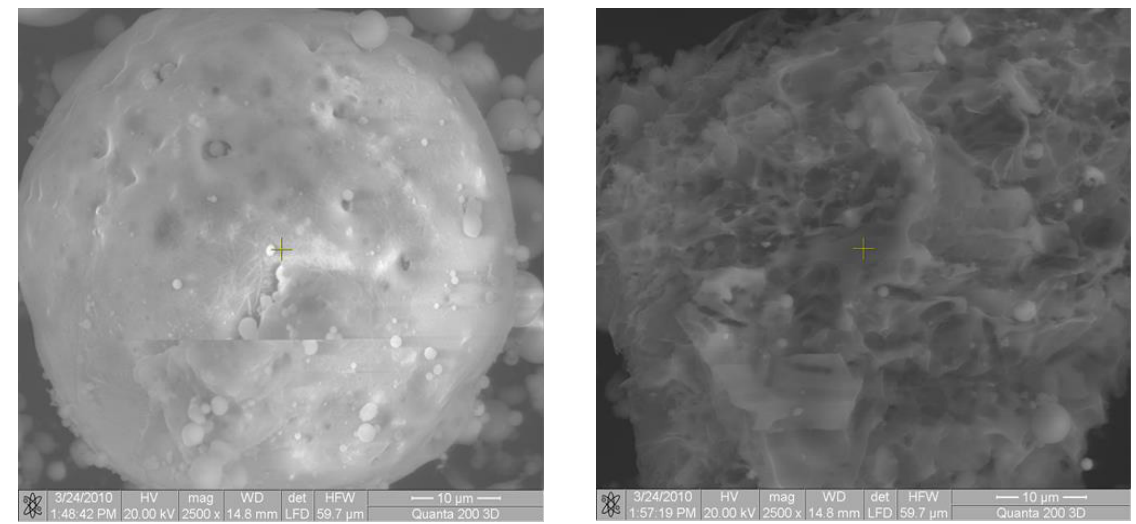

Fig. 3. Comparison between activation method and fusion method (G6 and G16).

At temperatures before $50^{\circ} \mathrm{C}$ is observed spherical unmodified ash particles, on these increases the new geopolymeric particles. Geopolymerisation degree is too significant at higher temperature, Fig. 4.
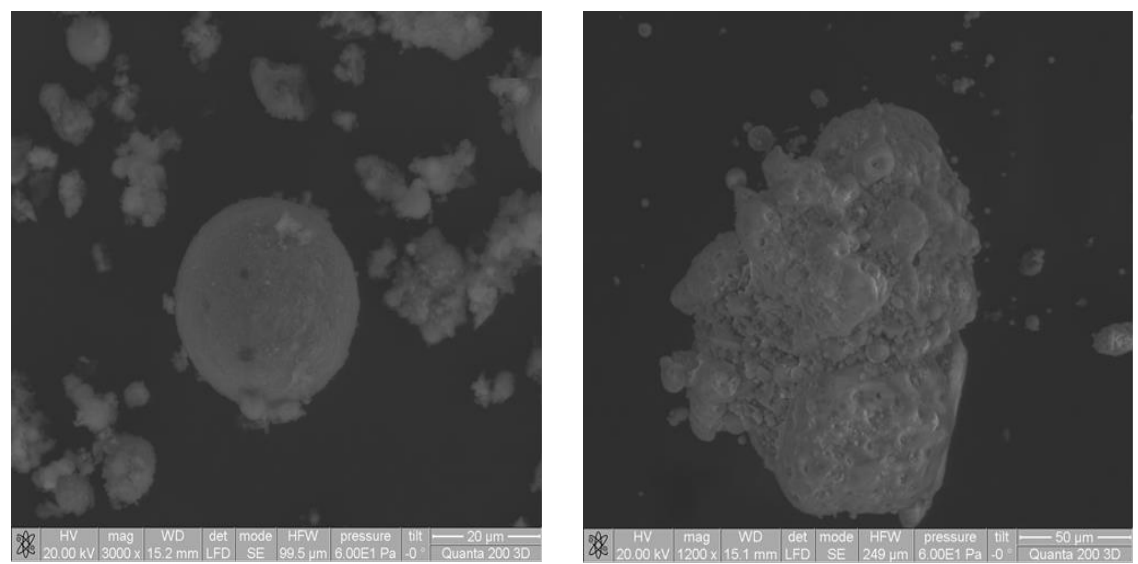

Fig. 4. Comparison between activation method and fusion method (G1 and G15).

Contact time influences the degree of geopolymerisation, Fig. 5. It were studied the influence of contact time at different temperature of curing.
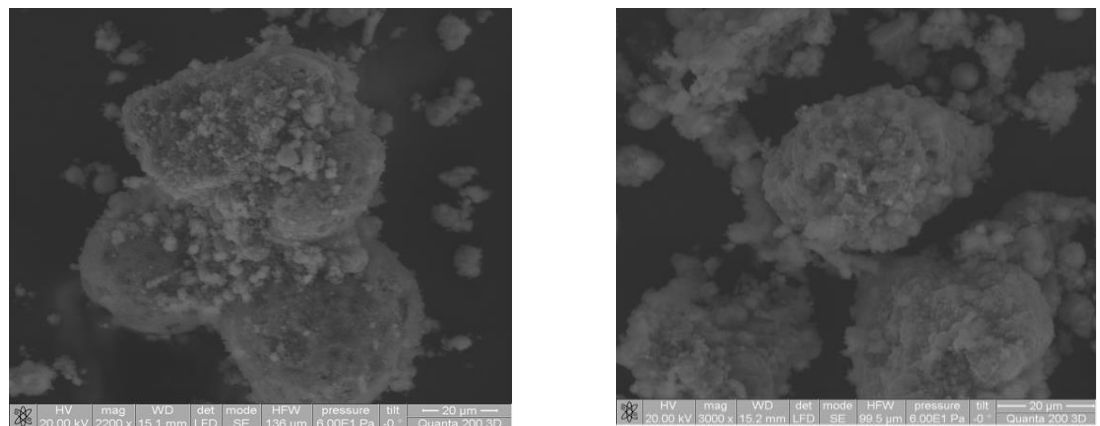

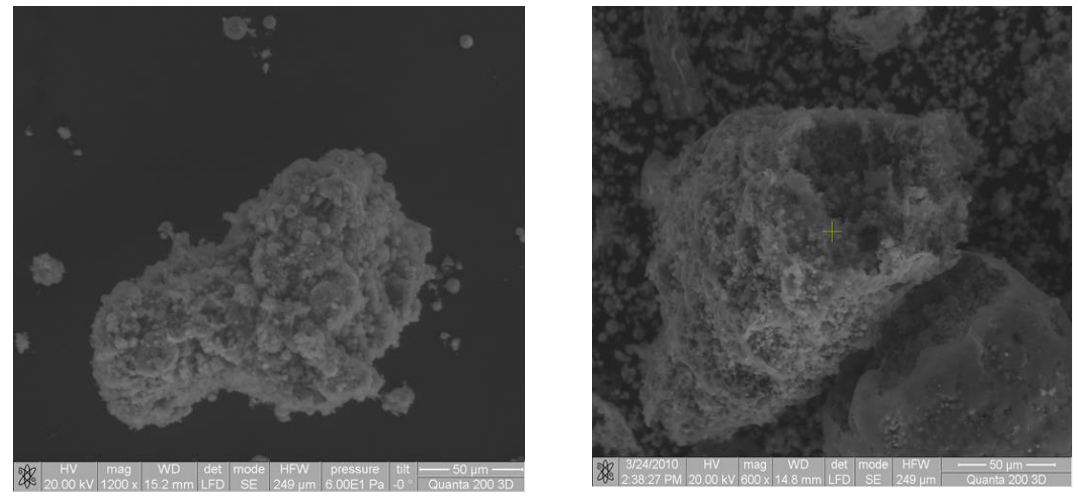

Fig. 5. Influence of the contact time (G5, G6, G13 and G14).

The synthetized geopolymeric materials contain multiple diffraction peaks (Fig. 6), that demonstrated appearance of new compounds compared with initial ash [26]. Identification of the peaks was performed according to the program PCPDF Win (1999). XRD analysis shows that the analyzed samples contain: quartz (Q), mullit (M), sodalite (S), feldspar (F), chabasite (Cha), clinotobermorit (CT), gismodine (Gis), Linde L (L) herchelite (Her), faujasit (Fau), Na-Y, tobermorite (T) [32]. From Fig. 6 it can be seen that sodalite was formed in all samples, it has a high stability at different temperatures [27]. It can be seen also that at materials synthesized at low temperatures peaks corresponding to quartz are intense, which demonstrated a relatively low degree of geopolymerization. Na-Y compound appear only at relatively high temperatures. G12 and G16 also shows, peaks corresponding Fau and Linde L.

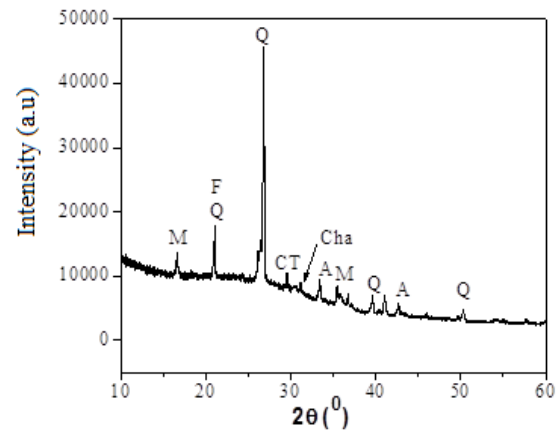

G2

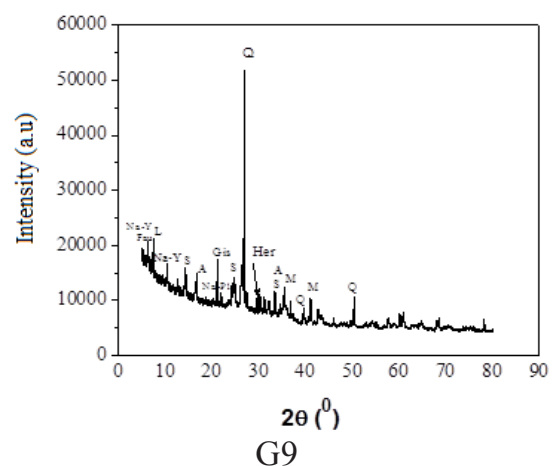

Fig. 6. XRD analysis for geopolymeric materials.

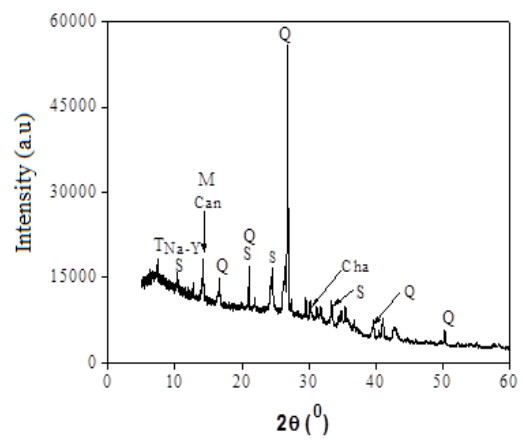

G6

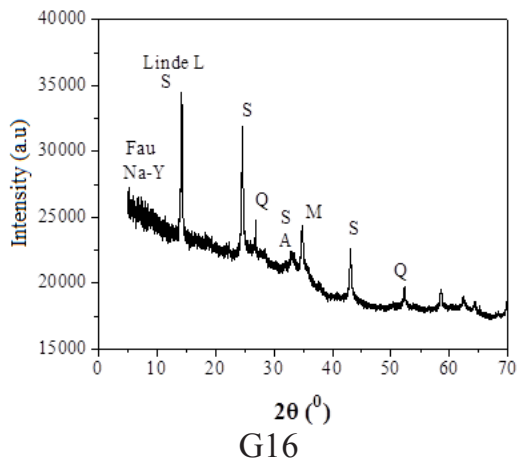


The trend of using of by-product materials, in the area of materials production, is likely when economic effectiveness increasing during fabrication [33]. In this context is necessary an economic evaluation of replacement of cement with geopolymer from fly ash as a possible alternative material [34]. The basic input is the cost of materials for the manufacture of geopolymer from fly ash as a substitute for cement. Evaluation is carried out based on analysis of the possibilities to reduce the total price of material costs with possible using in building material.

The method used for economic evaluation is the classical cost calculation. On the other hand, the cost of the geopolymer obtaining depends on the conditions of synthesis.

Our economic evaluation start from activation method at $80^{\circ} \mathrm{C}$, solid/liquid ratio $1 / 2$, $4 \mathrm{M} \mathrm{NaOH}$ solution, $4 \mathrm{~h}$ of treatment. Experimental results demonstrated that geopolymer namely G9 have chemical and technological characteristics, comparable with geopolymer obtained by diffusion methods, needed for used as cement replacement.

In actual context (capitalization of waste is priority), the price of one ton of fly ash is very cheap. The price of alkaline liquids needed to the make the geopolymer powder is 185-200 \$/t, water $1.05 \$ / \mathrm{m}^{3}$ and caloric energy $56.28 \$ /$ Gcal. The price needed for obtaining $1 \mathrm{t}$ of geopolymer powder is $77.07 \$$, in our country the price of Portland cement is $104.65 \$ / t$. In this condition the price of fly ash-geopolymer is with $26.3 \%$ cheaper than Portland cement, in accordance with literature estimated to 10 to 30 percent $[35,36]$.

The calculation does not take into consideration that the $\mathrm{NaOH}$ solution can be recycled, after concentration correction to $4 \mathrm{M}$. Then, if geopolymerisation is realized into the power plants would save the heating agent, flue gas at $120-140^{\circ} \mathrm{C}$ after the economizer, before eviction to desulphurization or discharged. With these improvements geopolymers becomes cheaper than Portand cement, ensuring significant savings in price and energy. On the other hand reduction of $\mathrm{CO}_{2}$ emissions caused by the cement industry, determine price reduction by carbon-credit that currently has a redemption value of about $5-6 \$ / \mathrm{eCO}_{2}$ [37].

\section{Conclusion}

Taking into account the concept of sustainable development, the by-product of one industry can be a raw material for other industries. The capitalization of waste has an important economic impact on the environment, by saving energy, raw materials and reducing pollution caused by storage of waste.

Having as objective a minimum consumption of energy and materials was developed a class of advanced eco-materials. New synthesized materials, having pozzolanic properties, can be used as a binder for cement replacement. It offers an advanced and low cost-effective solution to many problems, where waste must be capitalized.

The geopolymer formation, by hydrothermal route, is influenced by: temperature, alkali concentration, solid /liquid ratio, ash composition, time, $\mathrm{pH}$ etc.

Geopolymer samples were characterized by SEM, EDAX, FTIR, XRD, BET and pozzolanic activity. Regarding the characterization of synthesized materials we conclude:

- FTIR analysis demonstrated that the higher peak intensity was recorded for $6 \mathrm{M}$ alkali solution. The behavior of the FTIR peak of $6 \mathrm{M}$ sample indicated upper quantity of geopolymer formation at the first stage of the reaction.

- XRD spectra indicated that the intensity of crystalline phases was increased in alkali concentrated solutions.

- Phases like sodalite, faujasite, Na-Y were identified by XRD which are known phases of geopolymer/zeolite.

- Advanced destroyed of ash particles due to geopolymerisation reaction were observed from SEM study when pellets of $\mathrm{NaOH}$ were used and the temperature was higher. 
- At the constant temperature the percentage of geopolymer increases with increasing of curing time, from 4 to $48 \mathrm{~h}$.

- The price of fly ash-geopolymer is with $26.3 \%$ cheaper than Portland cement, it serves as a better alternative for replacement of Portland cement in the building industry.

Geopolymer materials are environmentally friendly, for its obtaining moderate energy consumption, and $\mathrm{CO}_{2}$ emission is reduced compared to ordinary cement binder.

This work was performed with the support of Doctoral school - Faculty of Chemical Engineering and Environmental Protection.

\section{References}

1. A. M.Aguirre-Guerrero, R. A. Robayo-Salazar, R. M. de Gutiérrez, Appl. Clay Sci. 135, 437 (2017)

2. T. Bakharev, Cem. Concr. Res. 35, 658 (2005)

3. Z. Abdollahnejad, F. Pacheco-Torgal, J.B. Aguiar, C. Jesus, Key Eng. Mater. 634, 113 (2014)

4. M. Harja, M. Bărbuţă, M. Gavrilescu, Env. Eng. Manag. J. 8, 513 (2009)

5. M. Harja, M. Bărbuţă, M. Gavrilescu, Env. Eng. Manag. J. 8, 1021 (2009)

6. E.A. Azimi, M.M. Al Bakri Abdullah, L.Y. Ming, H.C. Yong, K. Hussin, I.H. Aziz, Rev. Adv. Mater. Sci. 44, 273 (2016)

7. T. Bakharev, Cem. Concr. Res. 35, 1233 (2005)

8. J.C. Swanepoel, C.A. Strydom, Appl. Geochem. 17, 1143 (2002)

9. J. Davidovits, J. Davidovits (Ed.), Proceedings of the World Congress Geopolymer, Saint Quentin, France (2005)

10. A. Hajimohammadi, J. van Deventer, Waste Biomass Valor. 8, 225 (2017)

11. M. Barbuta, N. Taranu, M. Harja, Env. Eng. Manag. J. 8, 1145 (2009)

12. M. Harja, M. Barbuta, Adv. Sci. Letter 19, 455 (2013)

13. M. Criado, A. Fernández-Jiménez, A. Palomo, Micr. Mesop. Mater. 106, 180 (2007)

14. J. Davidovits, US Patent 4472199 (1984)

15. J. Davidovits, USPatent 4349386 (1982)

16. H.A. Abdel-Gawwad, S.A. Abo-El-Enein. HBRC J. 12, 13 (2016)

17. B.C. McLellan, R.P. Williams, J. Lay, A.Van Riessen, G.D. Corder, J. Cleaner Prod. 19, 1080 (2011)

18. A. Palomo, M.W. Grutzeck, M.T. Blanco, Cem. Concr. Res. 29, 1323 (1999)

19. G. Habert, J.B. D’Espinose de Lacaillerie, E. Lanta, N. Roussel, 2nd International Conference on Sustainable Construction Materials and Technologies (2010)

20. J. Davidovits, Concretes, 1, SRIBM, Kiev, Ukraine (1994)

21. A. Narayanan, P. Shanmugasundaram, Energ. Build. 138, 539 (2017)

22. I. Nikolić, M. Tadić, D. Đurović, R. Zejak, B. Mugoša, Env. Prot. Eng. 41, 2 (2015)

23. J. Giesekam, J.Barrett, P. Taylor, A. Owen, Energ. Build. 78, 202 (2014)

24. Z. Sarbak, M. Kramer-Wachowiak, Powder Technol. 123, 53 (2002)

25. M. Harja, M. Barbuta, L. Rusu, N. Apostolescu, Env. Eng. Manag. J. 7, 289 (2008) 
26. R. D. Bucur, C. Cimpeanu, M. Barbuta, G. Ciobanu, G.Paraschiv, M. Harja, J. Food Agric. Env. 12, 943 (2014)

27. F. Noli, G. Buema, P. Misaelides, M. Harja, J. Radioanal. Nuclear Chem. 303, 2303 (2015)

28. G. Buema, F. Noli, P. Misaelides, D. M. Sutiman, I. Cretescu, M. Harja, J. Radioanal. Nuclear Chem. 299, 381 (2014)

29. W.K.W. Lee, J.S.J. van Deventer, Langmuir 19, 8726 (2003)

30. C.A. Rees, J.L.Provis, G.C. Lukey, J.S.J. van Deventer Langmuir 23, 9076 (2007)

31. R.C. Ciocinta, M. Harja, D. Bucur, G. Buema, J. Food Agric. Env. 11, 1108 (2013)

32. S. Curteanu, G. Buema, C.G. Piuleac, D. M. Sutiman, M. Harja, J. Ind. Eng. Chem. 20, 597 (2014)

33. G. Mucsi, J. Lakatos, Z. Molnár, R. Szabó, The 9th International Conference "Environmental engineering (2014)

34. Š. Vilamová, M. Piecha, Acta Montan. Slov. 21, 139 (2016)

35. N.A. Lloyd, B.V. Rangan, 35th Conf. Our world in concrete \& Structures (2010)

36. D. Hardjito, B.V. Rangan, Research Report GC 1 (2005)

37. https://www.investing.com/commodities/carbon-emissions-historical-data 